ljeh Ikechukwu Boniface, Omeje Maxwell*, Oluchi Faith Onyeujo, Emmanuel Sunday Joel, Olusegun Oladotun Adewoyin, and Olukunle Charles Olawole

\title{
Mapping of Lineament Structures from Aeromagnetic and Landsat Data Over Ankpa Area of Lower Benue Trough, Nigeria
}

https://doi.org/10.1515/phys-2019-0070

Received Jul 05, 2017; accepted May 08, 2019

Abstract: Structural analysis of aeromagnetic and Landsat data over Ankpa area, Benue state was carried out to delineate the basement topography, hydrocarbon potentials, groundwater availability and the structures that control basin formation. The Landsat imagery generated from this study was further processed using Geomatica software (version 9.0). The results obtained revealed that the drainage pattern is dendritic which could be associated to the lithological, structural and topographic differences. Also, this may indicate the presence of alluvial rocks, typically of the same geology, mainly of sedimentary rocks. This present study is in good agreement with the areas in the lineament map of high-density structures. The observation showed that the study area constitutes densely lineaments that cut across each other, which may be attributed to groundwater availability and upward migration of hydrocarbon-bearing formation. The structural trend is predominantly in the NE-SW direction and agrees with the Landsat data structural trends. Significantly, this NE-SW trend is in agreement with the trend of Benue Trough (NE -SW) and could be that they have the same structural control.

\footnotetext{
^Corresponding Author: Omeje Maxwell: Department of Physics, College of Science and Technology, Covenant University, KM 10, Idiroko Road, Canaanland, Ota, Ogun State, Nigeria; Email: maxwell.omeje@covenantuniversity.edu.ng Ijeh Ikechukwu Boniface: Department of Physics, College of Science and Technology, Covenant University, KM 10, Idiroko Road, Canaanland, Ota, Ogun State, Nigeria; Michael Okpara University of Agriculture, Umudike, Umuahia, Abia State, Nigeria

Oluchi Faith Onyeujo: Michael Okpara University of Agriculture, Umudike, Umuahia, Abia State, Nigeria

Emmanuel Sunday Joel, Olusegun Oladotun Adewoyin, Olukunle Charles Olawole: Department of Physics, College of Science and Technology, Covenant University, KM 10, Idiroko Road, Canaanland, Ota, Ogun State, Nigeria
}

Keywords: lineament, Landsat, basement depth, Lower Benue Trough, drainage, aeromagnetic

PACS: $91.25 . Q i$, 43.40.ph, 93.85.-q, 07.88.+B

\section{Introduction}

The source and transformation of the Benue Trough are adequately reported $[5,6,8,19,21,27]$. They include the intersection of major lineaments or combination of both minor and major, local lineaments and tracing of extensive geographical lineaments. Features that are linear are clearly observable on aeromagnetic maps, which often-times signify the position and form of joints, lithologic, faults and distinct geologic attribute leading to the mineral deposits location [2], The use of remotely-sense data for hydrogeological studies is becoming well known most especially area where traditional method such as electrical resistivity technique is inadequate. The past application includes the work of $[4,9,11,16]$. Recently, there has been a successful joint application of remotely sensed data as a complementary technique with other conventional methods for hydrogeophysical studies $[1,12]$. There is still no single method of giving a unique solution for estimating the depth parameter because of the inherent ambiguity due to different subsurface sources. In this paper, we study the variation in depth estimation due to a single known source from two different measured components of the geomagnetic field. At some time-independent magnetic variations are established; which has been well known from adjoining effects, and this appearance may be a single magnetised body. The size and shape of this magnetic formation can be detected most effectively using quantitative methods. The depth framework, which is the most significant use of magnetic data [23] permits mapping of the topography and surface of basement rocks, likewise the sedimentary cover thickness [7]. This study aimed at integrating the aeromagnetic method and Landsat imagery to iden- 


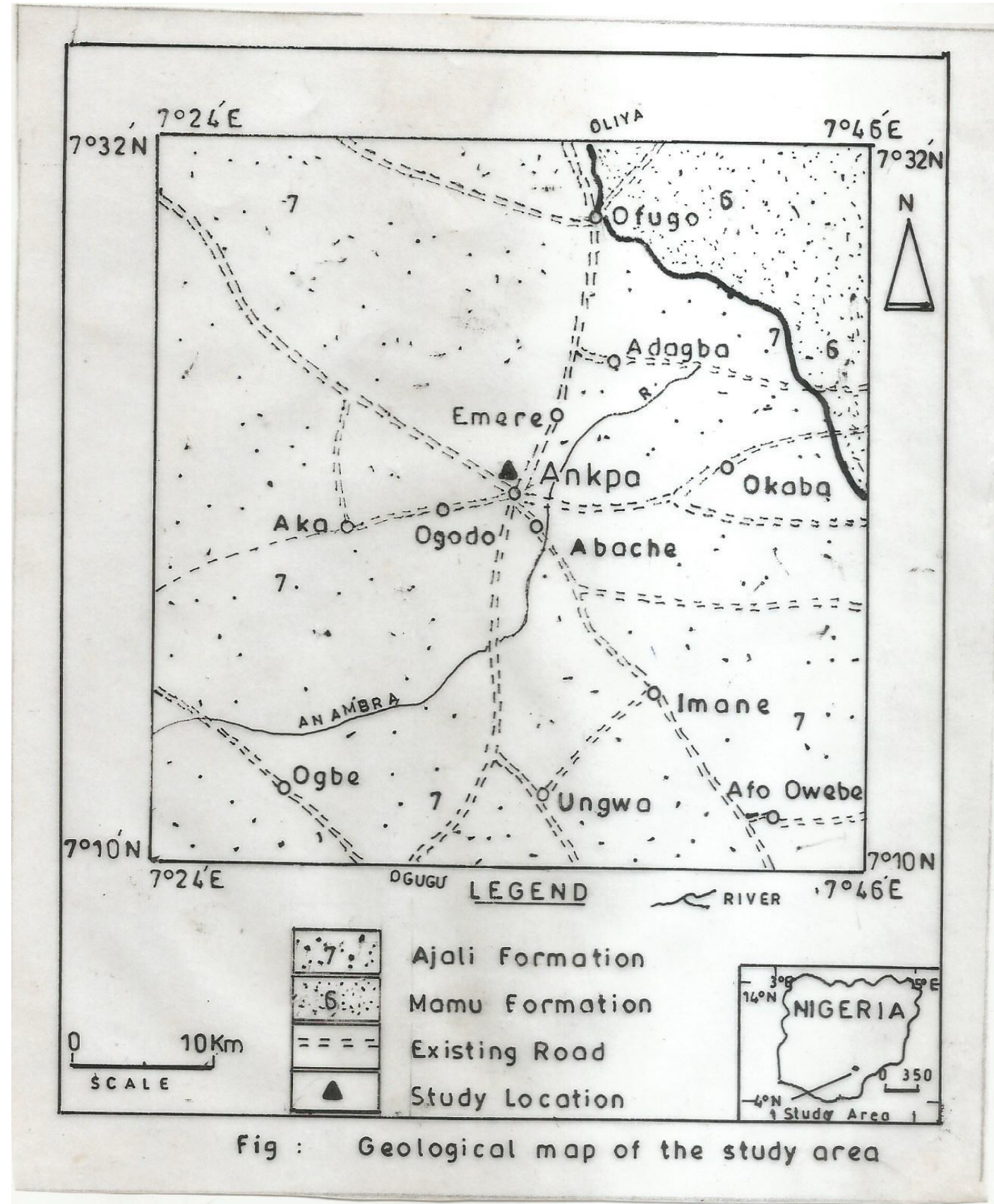

Figure 1: Geological map of the study area

tify the subsurface structure that controls the groundwater system as well as the features that could be trapped for hydrocarbon-bearing formation.

\section{Geology of the Study Area}

The study area is located within the Lower Benue Trough and lies within latitudes $7^{\circ} 10^{\prime} \mathrm{N}-7^{\circ} 32 \mathrm{~N}^{\prime}$ and longitudes $7^{\circ} 24^{\prime} \mathrm{E}-7^{\circ} 46^{\prime} \mathrm{E}$ (Figure 1). The geology of Ankpa is the geology of the Lower Benue Trough. The Benue Trough in Nigeria is a NE-SW trending sedimentary basin portioned geographically into Lower, Middle, and Upper Benue Trough 


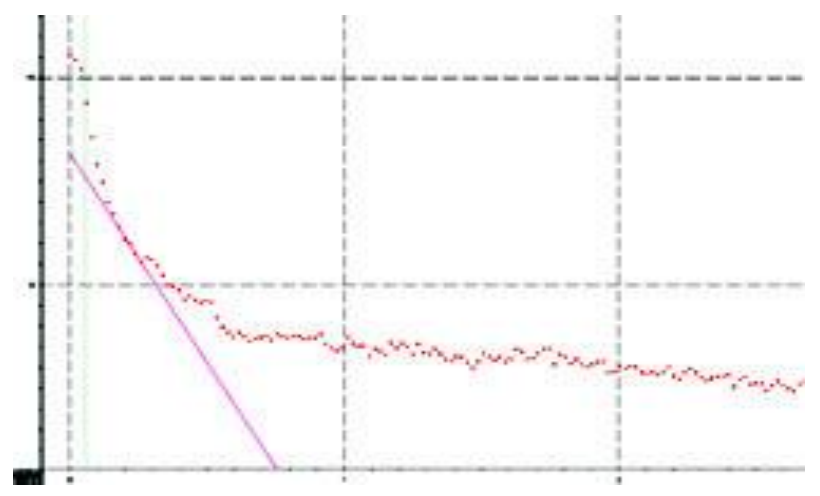

Figure 2: Showing a one-dimensional output of a power spectrum

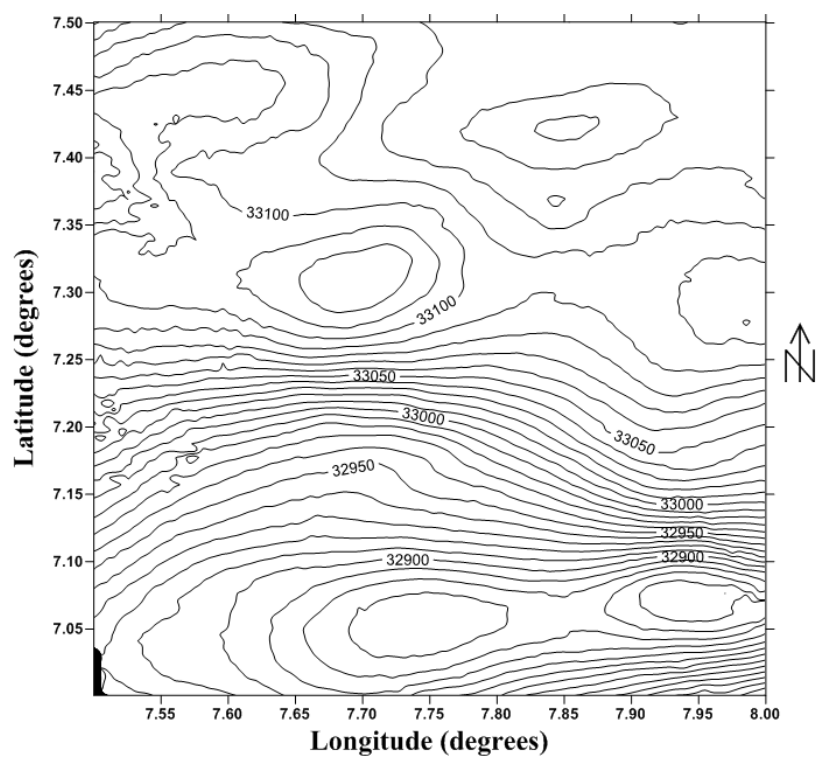

Figure 3: Contour map of the total magnetic intensity

that extends for about $1000 \mathrm{~km}$ in length with width ranging from $180 \mathrm{~km}$ to 250 [26].

\section{Theory and Methods}

Both Landsat and magnetic data share common features which serve as an interface for interpreting geological attribute which can be noted in between the features. Extensively, Landsat and magnetic data have been used as tools for reconnaissance survey in minerals and oil probe. In a similar vein, both have discontinuities at the surface noticed by the resemblance of the linear anomalies to surface faulting as evidence across the area.

Polynomial fitting is an entirely analytical technique that involves conjoins of the regional by a polynomial surface of low order which exposes the residual attribute as random errors. The system is based on statistical theory. In practice, the polynomial is rarely extended beyond the second order. An unswerving line usually typifies the regional field or generally, by a smooth polynomial curve. The least square technique is always used for the polynomial fitting. But, it should be well noted that this method has its inherent drawbacks which are:

1. Better fitting observations require a higher order of polynomials.

2. The unreasonable order of the polynomial is less than the number of the observations through which the curve passes wholly through all the data points but geologically has no meaning.

Other analytical methods used include 2-D spectral analysis. The use of spectral analysis in interpreting potential field data is one of the techniques that can be used to estimate the depth to the magnetic source which has been effectively well established [22]. Various researchers have used the method in the evaluation of the sedimentary thickness of basins around the world [18, 20, 24].

The derivation of power spectrum from the 2dimensional set of data namely Bouguer gravity data has a 2-dimensional form. For easy interpretation, the mean of azimuthal of the 2-dimensional power spectrum is estimated to generate a simple 1-dimensional output as represented in Figure 2. Occasionally the power spectrum may be grouped into 2 or more unswerving line segments. The inclination of each segment can be interconnected to the depth of group of anomalous origins which are in the range of spatial frequencies as defined by the segment.

\subsection{Materials and Methods}

The aeromagnetic map of Ankpa was obtained from the Nigerian Geological Survey Agency (NGSA). The halfdegree sheet data $\left(7^{\circ} 00-7^{\circ} 30 \mathrm{~N}\right.$ and $\left.7^{\circ} 30-8^{\circ} 00 \mathrm{E}\right)$ and in the scale of 1:100000, were acquired at a flight altitude of $80 \mathrm{~m}$, along NE-SW flight lines that were spaced at $500 \mathrm{~m}$. The spatial variation effect in the geomagnetic field caused by the geomagnetic field derived from the outer core of the earth was removed [16]. The total magnetic field intensity range between 32350 and $66900 \mathrm{nT}$ (see Figure 3). Most of the anomalies trend NE-SW, but some most especially at the southern segment of the map, trend E-W. A very high magnetic intensity was observed between latitude $7^{\circ} 00$ $7^{\circ} 2.4 \mathrm{~N}$, and longitude $7^{\circ} 30^{\prime}-7^{\circ} 36 \mathrm{E}$ (Figure 3 ).

The data obtained from the digitised aeromagnetic total intensity field map are run on the 2xyz program of the United States Geological Service (USGS) Potential Field 
method (Version 2.2 software) to convert the binary numbers to post files called PST files. The maps used were computed on a mesh of $1 \mathrm{~km}$ imposing a Nyquist Frequency of $1 / 2 \mathrm{~km}^{-1}$ so that magnetic attribute that is restricted may be clarified by the computed data which has a thickness of $2 \mathrm{~km}$. The anomalies are broad above $2 \mathrm{~km}$ and lie in a range of frequency from aliasing, which does not exist with a $1 \mathrm{~km}$ computerising grid. Consequentially, the aeromagnetic map was computed in such a way that the information was saved in $55 \times 55$ sheets that were coded. Each of the records consists of boundary latitudes and longitudes, the number of maps and the town's name of overflow. The data were recorded inside a computer file; subsequently, turn to be the input file for a computer program. The data points were picked row by row, their longitude and latitude were calculated and the coordinates for magnetic value respectively. The output file for each of this performance was named for easy recognition. The 3dimensional coordinates which are $\mathrm{x}, \mathrm{y}, \mathrm{z}$, is allowed to be convenient for a contouring package "Detour program, a Fortran 77 program." A total of 75 lineaments were digitised on screen and displayed on the lineament map of the study area. Visualising the interpretation of the distribution of lineament reveal that the eastward of the map fell within the lower Benue Trough and was observed in the Landsat - TM data. The analysis was done in such a way that would enhance the trends and smoothen the computing of depths to basement rocks and locations.

\section{Results and Discussion}

\subsection{Magnetic Interpretation of the Study Area}

The magnetic anomalies fields merge the effect of horizontal variation of magnetic polarization inside the earth, and consequently, the anomalies of portion in a precise geologic approach are normally contorted by anomalies overlapping. The geomagnetic anomaly fields include effects of deeper, wider pedigrees (sources) called regional anomalies: local sources which are considered noise as well as the anomalies of interest - the so-called residual anomalies. The separation of residual anomaly from the geopotential field is a critical problem which may control the accuracy of the interpretational process [15].

The least square method was adopted in this work out of several techniques like geologic method, profile method etc. The least squares criterion regional-residual separation is such that the residual is the square of the deviation

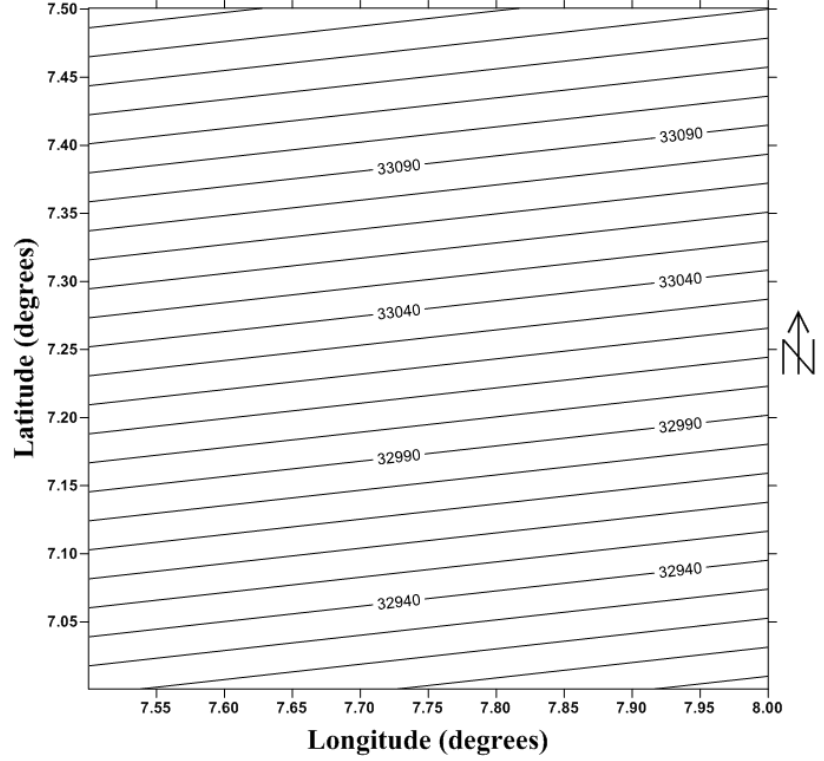

Figure 4: First degree regional magnetic intensity map of study area

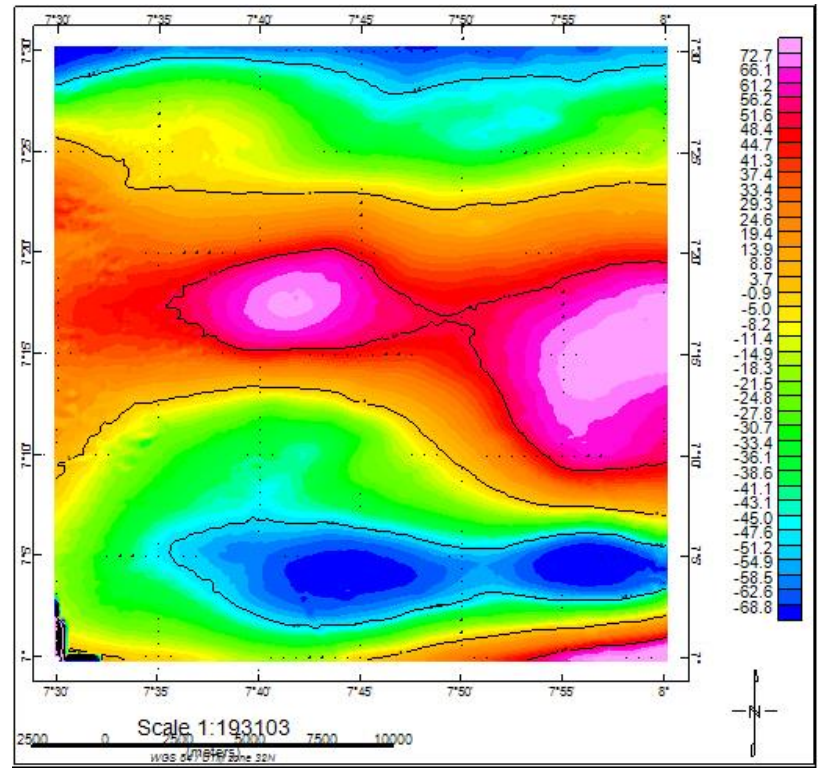

Figure 5: First degree residual magnetic intensity map of study area

of the regional from the observed (measured). The regional usually a polynomial surface exposes the residual features as the deviation from the observed field. The separation of a data into two component is done by fitting a trend (plane) surface, which may be defined as a linear function of the geographic coordinates of a set of observations (in this case, total magnetic field data) so constructed that the squared deviations from the trend are minimised. Figures 4 and 5 showed respectively the regional and residual fields after the least-square operation has been performed on the aeromagnetic data. The value of the regional field 

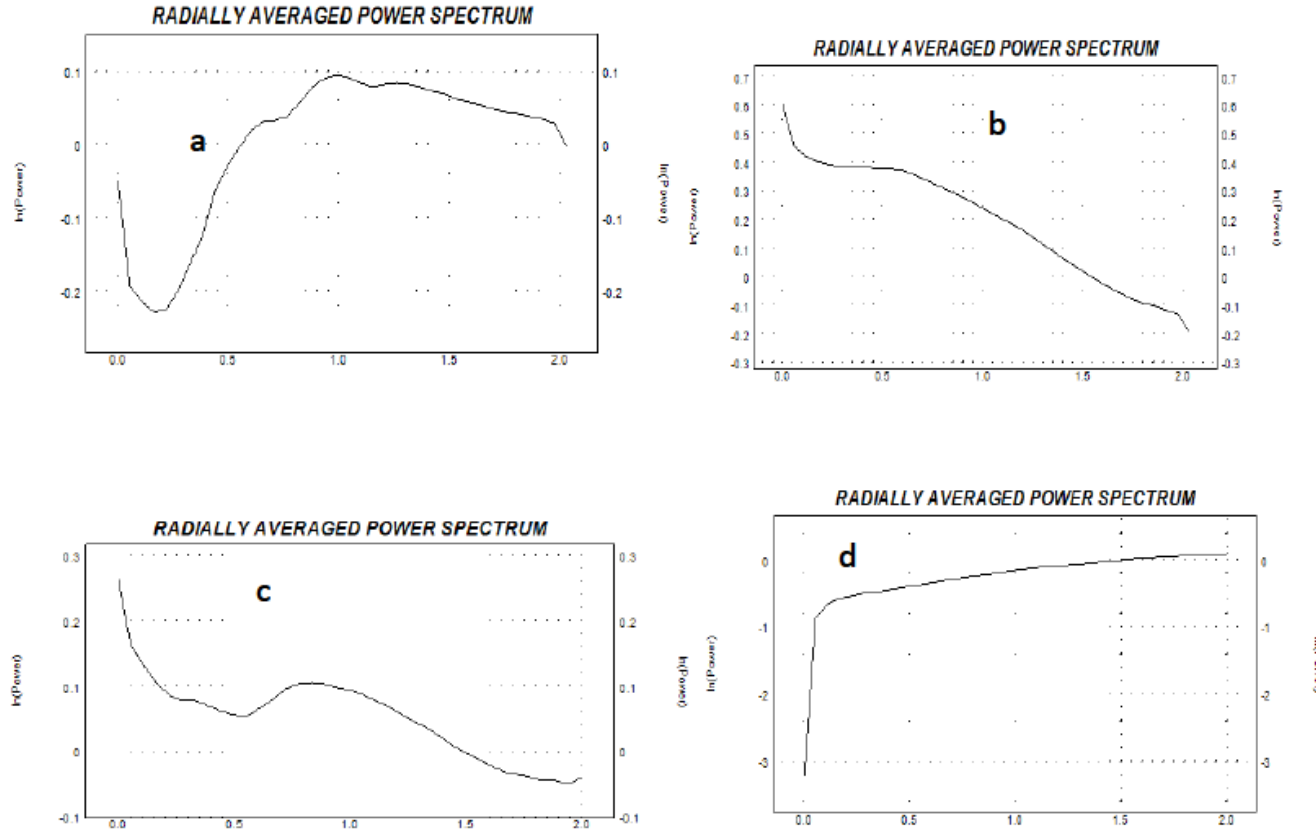

Radian $/ \mathbf{k m}$

Radian/km
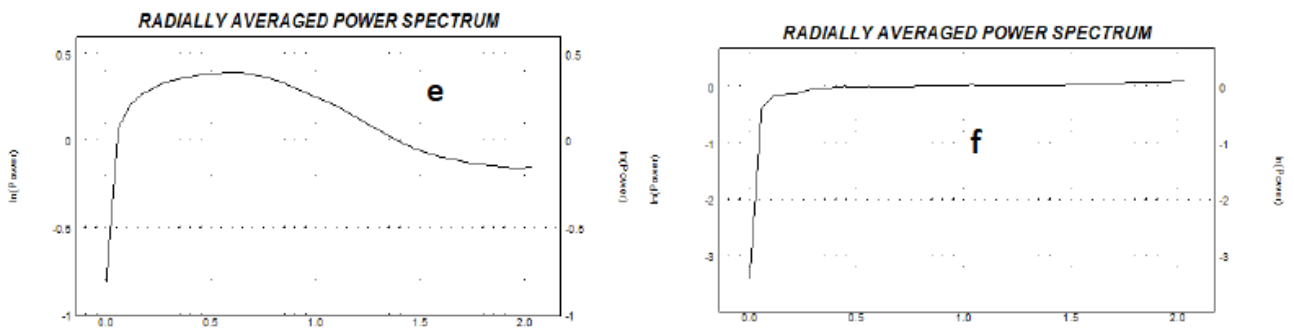

Radian/km

Radian $/ \mathrm{km}$
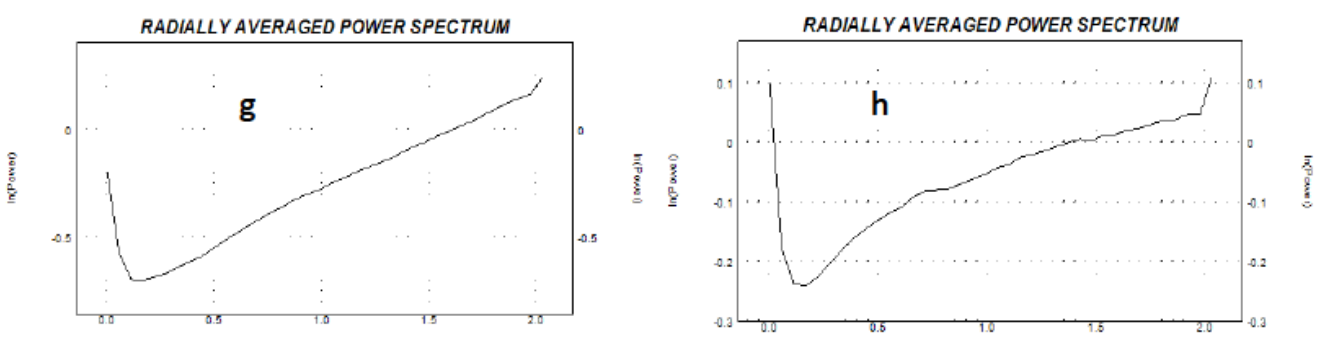

Radian/km

Radian/km

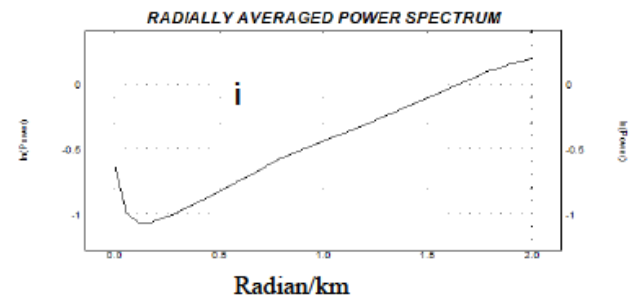

Figure 6: Power spectrum plot of aeromagnetic data of blocks 1-9 


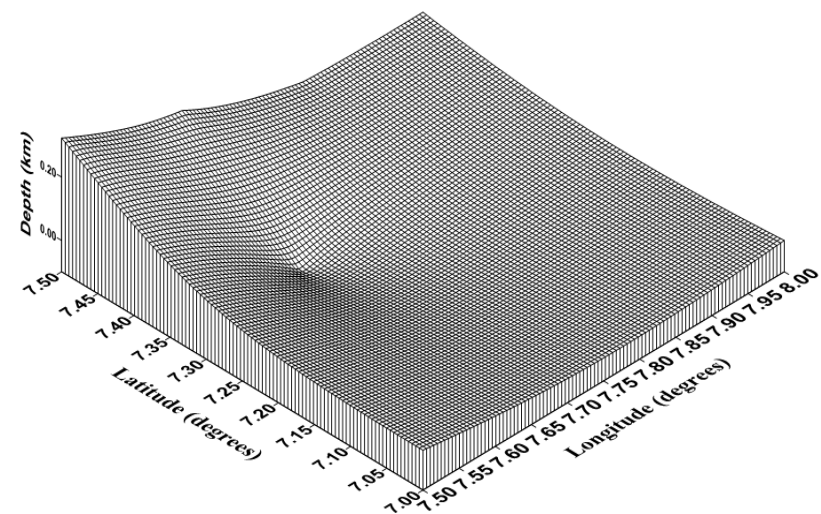

Figure 7: 3-D map of the depth to shallow magnetic sources in the study area

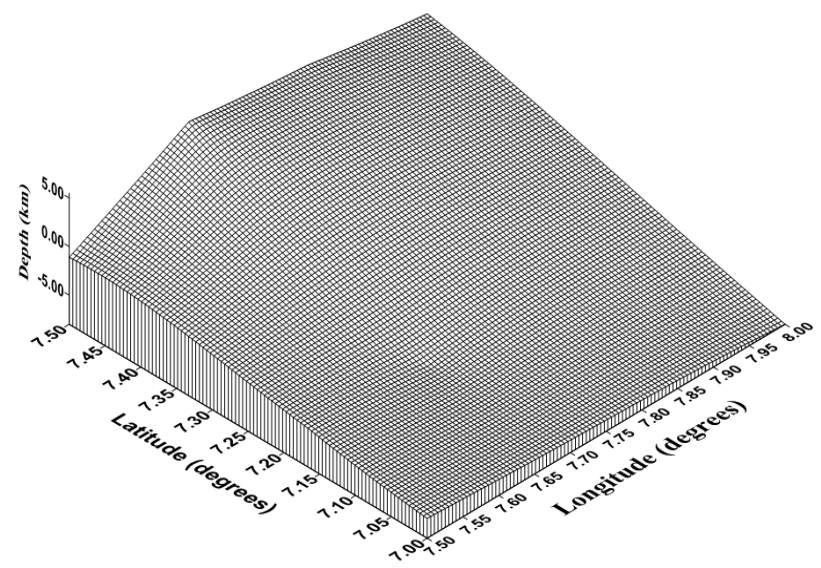

Figure 8: A 3-D map of the depth to deeper magnetic sources in the study area

(Figure 4) increases gradually from the SE section to the NW of the study area, and the trend pattern in the regional field shows an NW-SE trend which conforms to major tectonic structures.

\subsection{Depth estimation method}

The depths to both shallow and deep magnetic sources were investigated using the spectral technique. This was achieved by splitting the whole data into nine blocks using window size by subjecting them into the spectral analysis as shown in Figures $6(\mathrm{a}-\mathrm{i})$ below.

The depths are indicated in the Table 1, and the depth distributions for both shallow and deep sources are shown in Figures 7 and 8 respectively. Bodies in the north-eastern region are deeper (see Figure 8) while those of the southwestern region of the study area is shallower as shown in Figure 7.
Table 1: The depths to magnetic source

\begin{tabular}{ccccccc}
\hline $\begin{array}{c}\text { Spectral } \\
\text { blocks }\end{array}$ & \multicolumn{1}{l}{ Longitude } & \multicolumn{2}{c}{ Latitude } & \multicolumn{2}{c}{ Depth (km) } \\
\hline & $\mathrm{X}_{1}$ & $\mathrm{X}_{2}$ & $\mathrm{Y}_{1}$ & $\mathrm{Y}_{2}$ & $\mathrm{D}_{1}$ & $\mathrm{D}_{2}$ \\
$\mathrm{~A}$ & 7.500 & 7.667 & 7.500 & 7.337 & -1.100 & 0.323 \\
$\mathrm{~B}$ & 7.667 & 7.834 & 7.500 & 7.337 & 5.5 & 0.180 \\
$\mathrm{C}$ & 7.834 & 8.000 & 7.500 & 7.337 & 4.000 & 0.040 \\
$\mathrm{D}$ & 7.834 & 8.000 & 7.337 & 7.167 & 0.000 & 0.000 \\
$\mathrm{E}$ & 7.667 & 7.834 & 7.337 & 7.167 & 0.100 & -0.100 \\
$\mathrm{~F}$ & 7.500 & 7.667 & 7.337 & 7.167 & 0.000 & 0.000 \\
$\mathrm{G}$ & 7.500 & 7.667 & 7.167 & 7.000 & -4.000 & 0.000 \\
$\mathrm{H}$ & 7.667 & 7.834 & 7.167 & 7.000 & -5.000 & 0.000 \\
$\mathrm{I}$ & 7.834 & 8.000 & 7.167 & 7.000 & -8.000 & 0.000 \\
\hline
\end{tabular}

The resulting analysis of the Landsat Imagery for the lineament extraction revealed several lineaments ranging in length from $1 \mathrm{~km}$ to $6 \mathrm{~km}$ with a predominant trend in the NE - SW, and some secondary trends in the NW - SE, $\mathrm{E}-\mathrm{W}$ and $\mathrm{N}-\mathrm{S}$ directions. Surface trend analysis of the tectonic and structural features of the area shows that the drainage pattern is structurally controlled due to its dendritic pattern and its direction of flow which corresponds to the trend of the lineaments. The area has rugged geomorphology as shown in the Shaded Relief Map. The lineament trends correspond to faults, geologic boundaries, folds and tectonically related joints in the area causing the ruggedness of the topography. Also, a lineament density map was generated to highlight areas with a high prevalence of the structures and overlaid on the image. For the Structural Lineament Map, it could be seen that most of the structures are situated around the drainage system of the area, which is a contributing factor to its dendritic nature.

Figure 9 presents the lineament map of the study area. It indicates several densely populated lineament trends with most of them interconnecting each other. The trending is more of NE-SW and NW-SE respectively. These highdensity fractures or lineaments could be a groundwater channel in the study area. Other minerals could still be identified with these intense fractures joining from one end to the other. Linking this lineament with the residual field map in Figure 5, the locations with high residual magnetic anomaly which indicates high magnetic susceptibility of magnetic features was noted with high fractural trends which could be a potential zone for groundwater resources in the study area.

Figure 10 presents the shaded relief image map of the region showing how the subsurface features control the regional field. It can be observed that this effect was much 


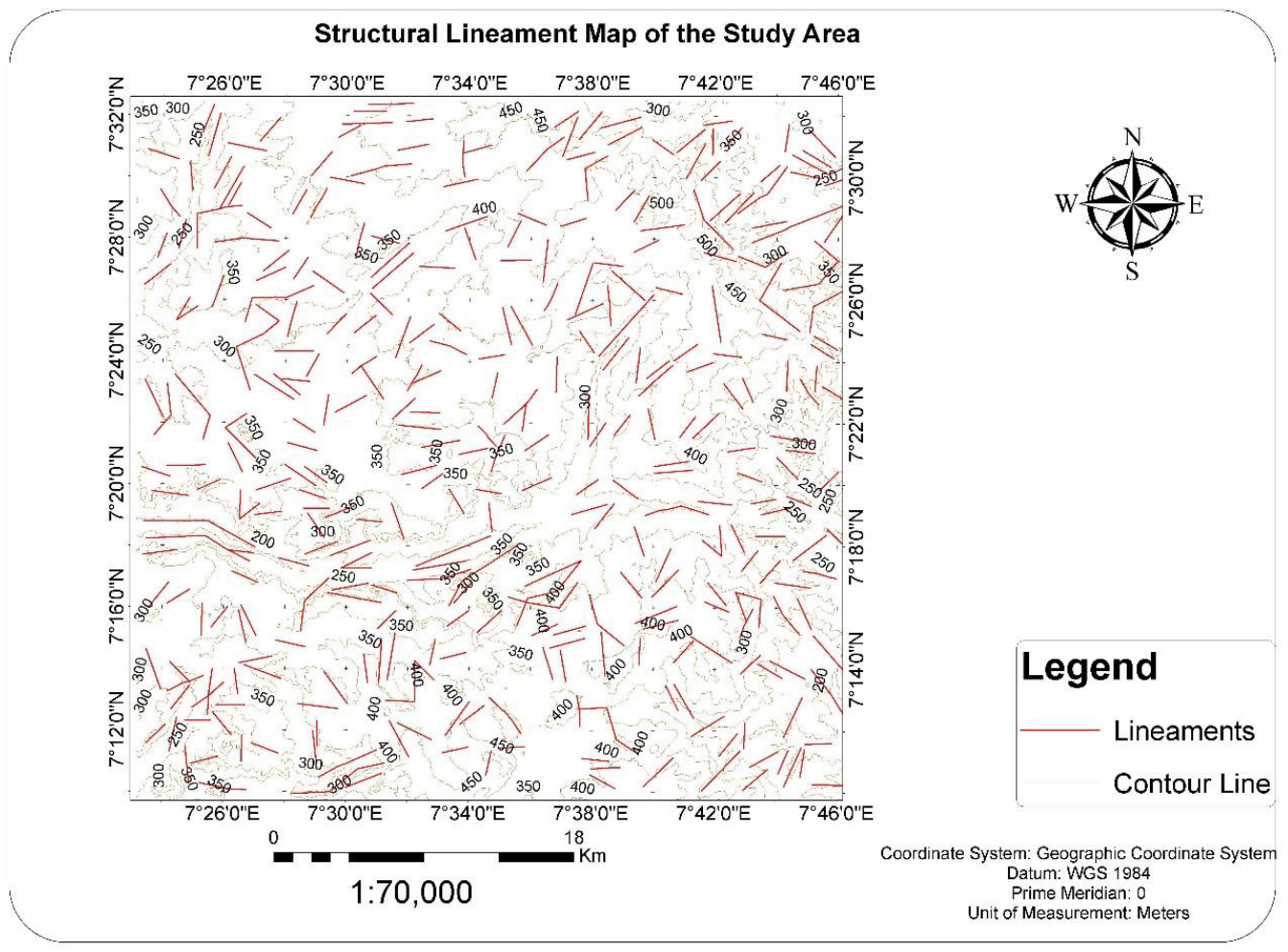

Figure 9: Structural Lineament Map of the study area

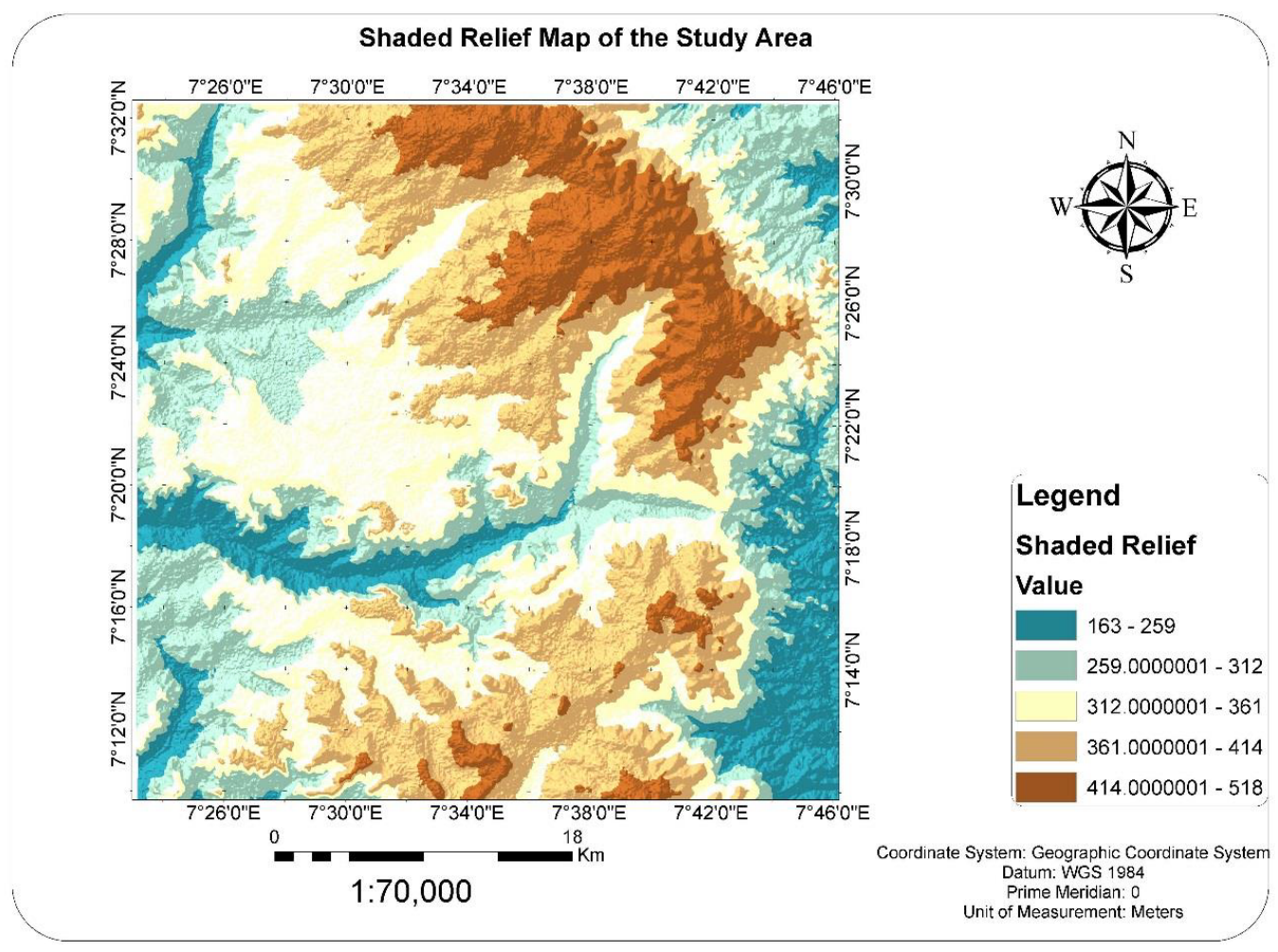

Figure 10: Shaded Relief Image of the Study area 


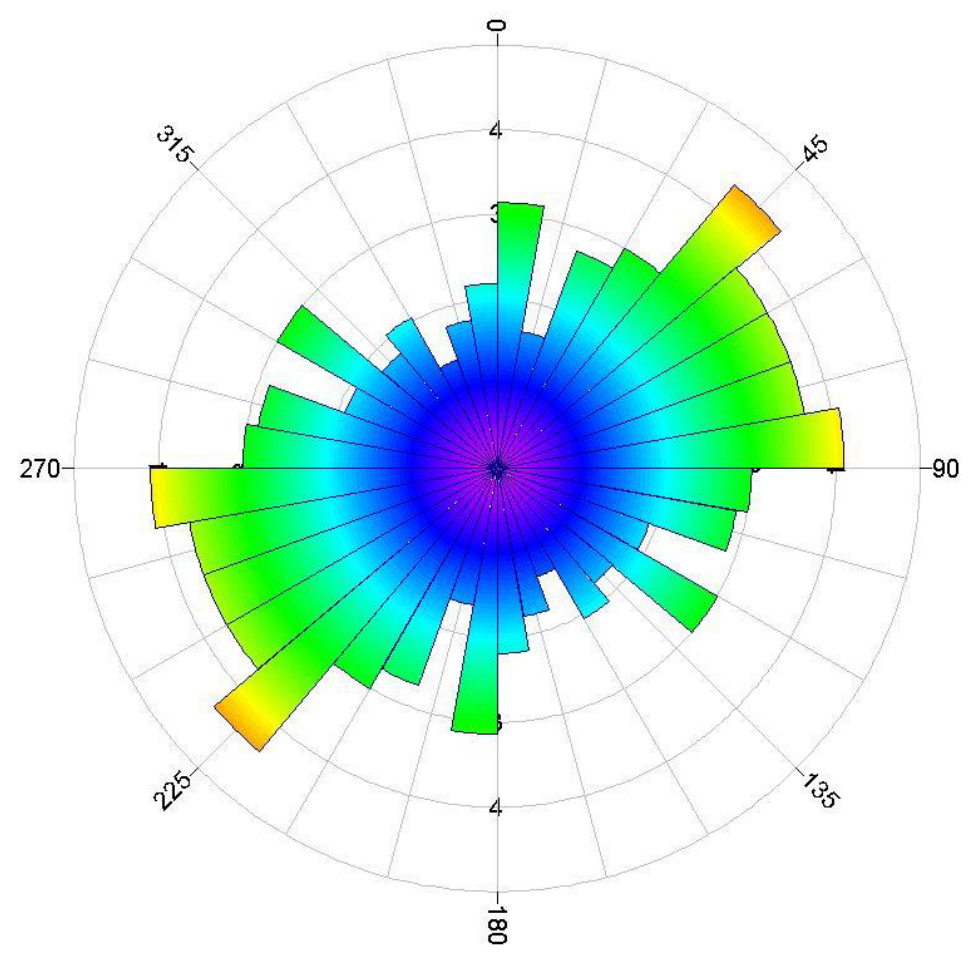

Rose Diagram

\begin{tabular}{|r|r|}
\hline \multicolumn{2}{|c|}{ Statistical Summary } \\
\hline Calculation Method: & Frequency \\
\hline Class Interval: & 10.0 Degrees \\
\hline Azimuth Filtering: & Deactivated \\
\hline Data Type: & Bidirectional \\
\hline Rotation Amount: & 0.0 Degrees \\
\hline Population: & 366 \\
\hline Total Length of All Lineations: & 732.0 \\
\hline Maximum Bin Population: & 32.0 \\
\hline Mean Bin Population: & 20.33 \\
\hline Standard Deviation of Bin Population: & 6.55 \\
\hline Maximum Bin Population (\%): & 4.37 \\
\hline Mean Bin Population (\%): & 2.78 \\
\hline Standard Deviation of Bin Population (\%): & 0.89 \\
\hline Maximum Bin Length: & 32.0 \\
\hline Mean Bin Length: & 20.33 \\
\hline Standard Deviation of Bin Lengths: & 6.55 \\
\hline Maximum Bin Length (\%): & 4.37 \\
\hline Mean Bin Length (\%): & 2.78 \\
\hline Vector Mean: & 66.0 Degrees \\
\hline & 245.96 Degrees \\
\hline Standard Deviation of Bin Lengths (\%): & 0.89 \\
\hline Confidence Interval: & 21.9 Degrees \\
\hline & (95 Percent) \\
\hline R-mag: & 0.19 \\
\hline
\end{tabular}

Figure 11: Rose Diagram

on the NE-SE region of the study area (Figure 11). This region may have been affected by the deep-seated features from the basement and shave off the NW-SW region (Figure 11). The NE-SE of the major effect could be potentials for mineral deposits and other intrusive materials of economic importance in the study area. These effects masked of the sedimentary which is confirmed in 3D residual fields found in Figures 7 and 8 respectively.

The 3D depth to the magnetic sources indicates high and low zones which could be basements and sedimentary features in the study area. The truncation from the North to the South, deep towards the South could be the effect of the upper Benue valley as an indication of river channels implications in the region. The sedimentary region may have been affected by the gulley erosions and could be a source of a contaminant if groundwater is tapped in that direction. The effect of the shallow sources as indicated in the 3D map above could be a magnetic intrusion. It can be observed that a deep intrusion with a high-density mark is noted in the western part of the study area. This deep gulley nature of intrusion may be attributed to basaltic intrusion. The effect is noticed from SW through the SE region of the study area.

\section{Conclusion}

The results obtained from this study revealed the orientation of the lineaments to be NE-SW trending and in agreement with the trend of the Benue Trough. It could be that they have control of the same structure. It was noted that the depth variation of the study area; the western part through the eastern region is deeper whereas the south-western region is shallower which could be the features of basaltic intrusions. The dense interconnectivity of fractures noted in the lineament map could be a potential for groundwater aquiferous zone. The deep gully point in shallow source map could be a potential trap for the hydrocarbon-bearing formation and groundwater channels.

Acknowledgement: The authors would like to thank Covenant University for their financial assistance in making this research to be viewed in scientific community. Also, thanks to the Federal University of Agriculture, Umudike for the financial support in executing this research at the University. 


\section{References}

[1] Anudu G. K., Essien B. I., Onuba L. N. and Ikpokonte A. E., Lineament analysis and interpretation for assessment of groundwater potential of Wamba and adjoining areas, Nasarawa State, north central Nigeria. Journal of Applied Technology in Environmental Sanitation, 1, 2011, 185 -198.

[2] Anyanwu G. and Mamah L., Structural interpretation of AbakalikiUgep using Airborne magnetic and Landsat thematic mapper (TM) data. Journal of natural sciences research, 3 (13), 2013, 137146.

[3] Bala A. E., An evaluation of Landsat 5 thematic mapper data as a tool for groundwater investigation in basement complex rocks of Nigeria, Unpublished Ph.D Thesis, Ahmadu Bello University, Zaira, Nigeria, 2011.

[4] Bala A. E., Batalan O. and De Smedt F., Using Landsat5 imagery in the assessment of groundwater resources in the crystalline rocks around Dutsin-Ma, Northwestern Nigeria. Journal of Mining and Geology, 36, 2001, 85-92.

[5] Benkhelil J., Structure et evolution geodynamique du Basin intracontinental de la Benoue (Nigeria) Bull. CentresRech.,Explor. Prod. Elf Aquitaine 1207, 1988, 29-128.

[6] Benkhelil J., The Origin and Evolution of the Cretaceous Benue Trough (Nigeria), Journal of African Earth Sciences, 8, 1989, 251282.

[7] Breiner S., Applications Manual for Portable Magnetometers: GeoMetrics, Sunnyvale, California, 1973.

[8] Burke K.G., Dessauvagie T.F.J. and Whiteman A.J., Opening of the Gulf of Guinea and Geological History of the Benue Depresssion and Niger Delta Nature (Phy. Sc), 233, 1971, 51-55,233.

[9] Edet A, Oden M. I. and Efretuei O. E., Correlation between core penetration in parts of coastal plain sands, S.E. Nigerai, Bulletin of the International association of Eng. Geology, Paris 49, 1994, 41-45.

[10] Finlay C.C., Maus S., Beggan C.D., International Geomagnetic Reference Field, $11^{\text {th }}$ generation, Geophysical Journal International, 183, 2010, 1216-1230, https://doi.org/10.1111/j.1365246X.2010.04804.X

[11] Galnett R. H. and Gardner J. V., Use of radar for groundwater exploration in Nigeria, West Africa. Proceedings of the 14th International Symposium on Remote Sensing of Environment, Ann Arbor, Michigan, USA. 1979.

[12] Goki N. G., Ugodulunwa F. X. O., Ogunmola J. K., Oha I. A. and Ogbole J. O., Geological controls for groundwater distribution in the basement rocks of Kanke, central Nigeria from geophysical and remotely sensed data, African Journal of Basic and Applied Sciences, 2, 2010, 104-110.
[13] Guariglia E., Fractional Derivative of the Riemann Zeta Function, in Fractional Dynamics, Cattani, Srivastava, Yang (Eds.), De Gruyter, 2015, 357-368.

[14] Guariglia E. and S. Silvestrov, A functional equation for the Riemann zeta fractional derivative, AIP Conference Proceedings 1798, 020063.

[15] Hinze W.J., The Role of Gravity and Magnetic Methods in Engineering and Environmental Studies, In Ward; S.H., Ed., Geotechnical and Environmental Geophysics, Society of Exploration Geophysicists, 1990, 75-126.

[16] Finlay C.C., Maus S., Beggan C.D., Hamoudi M., Lesur V., Lowes F.J., Olsen N., Thébault E., Evaluation of candidate geomagnetic field models for IGRF-11, Earth Planets Space IGRF Special issue 62(10): 2010b. 787-804

[17] Joel E.S., Olasehinde P.I., Adagunodo T.A., Omeje M., Akinyemi M.L., Ojo J.S., Integration of aeromagnetic and electrical resistivity imaging for groundwater potential assessments of coastal plain sands area of Ado-Odo/Ota in southwest Nigeria, Groundwater for Sustainable Development, 9, 2019, 100264.

[18] Kangoko R., Ojo S.B. and Umego M.N., Estimation of basement depths in the Middle Cross River Basin by spectral analysis of the aeromagnetic field. Nig. Journ. Of Physics, 9, 1997, 30-36.

[19] Nwachukwu S.O., The Tectonic Evolution of the Southern Portion of the Benue Trough, Nigeria. Geology Mag, 109, 1972, 411-419.

[20] Ofoegbu C.O., and Onuoha K.M., Analysis of Magnetic Data over the Abakiliki Anticlinorium of the Lower Benue Trough, Nigeria. Marine and petr. Geol., 8, 1991, 174-183.

[21] Olade M.A., Evolution of Nigeria's Benue Trough (aulacogen): A tectonic model, Geol. Mag., 112, 1975, 576-583.

[22] Spector A. and Grant F.S., Statistical Models for interpreting Aeromagnetic Data, Geophysics, 35, 1970, 293-294.

[23] Thompson D.T., EULDPH - A new technique for making computerassisted depth estimates from magnetic data: Geophysics, 47, 1982, 31-37, doi: 10.1190/1.1441278.

[24] Udensi E.E, Osazuwa I.B., Spectral determination of depths to magnetic rocks under the NupeBasin, Nigeria. NAPE Bull 17, 2004, 22-27.

[25] Turcotte D. L, Fractals and Chaos in Geology and Geophysics, Cambridge University Press, 2007, 14-218.

[26] Whiteman A., Nigeria: its Petroleum resources and potential. Graham and Trotham, London, 1982.

[27] Wright J.B., South Atlantic Continental Drift and Benue Trough tecnophsics 6, 1968, 301-31. 